\title{
滑覆剪切作用形成的剑鞘褶皱 *
}

王桂梁 姜 波 余志伟

(中国矿业大学地质系, 徐州 221008)

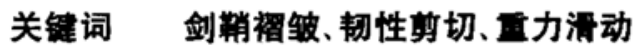

剑鞘袮皱 (sheath fold) 由 Carreras 研究比利牛斯海西期褶皱带中提出 ${ }^{[1]}$ 之后, 一直作 为深层次韧性剪切带鉴别标志 (之一) 而被世界所公认 ${ }^{[2,3]}$. 最近国际上也只是在深层次 变质岩中见到有关这类的构造现象 ${ }^{[4-6]}$. 我国东南在浅层脆性构造域的二叠系煤系地层中, 见 到由重力作用的滑覆剪切形成的非常典型的剑鞘褶坡[7].

\section{1 形 态 特 征}

下二叠统童子岩煤系中的剑鞘褶坡主要发育于层理发育、并含有泥质夹层的薄层砂岩 中. 它位于政和 - 大埔断裂以西龙岩市东翠屏山矿区的翠峰沟和大田县上京矿区的望仙亭等 地区 (图 1). 它们规模巨大、形态完好, 见于公路拐弯处的两个相互垂直的露头上. 在垂直 $y$ 轴的 $x, z$ 面上它们是两翼平直、翼间角较小的尖棱状或尖圆状的平卧或斜卧褶曲; 而且连续发

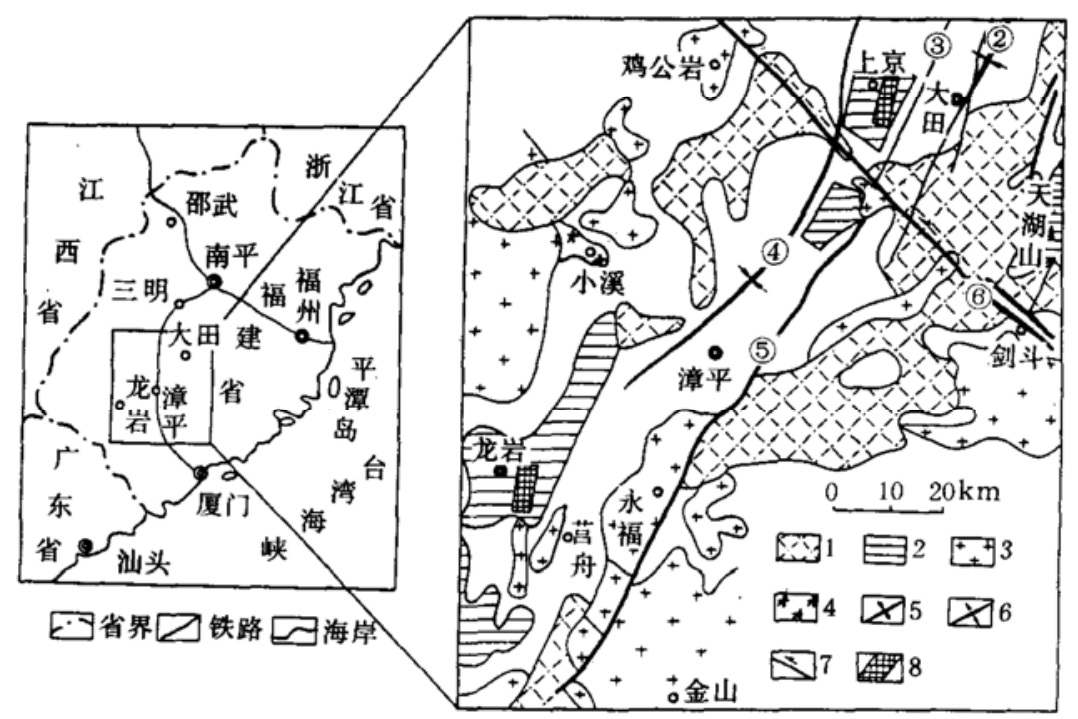

图 1 福建省翠屏山及上京矿区位置交通及区域地质简图

1 一上侏罗统火山岩; 2 一下二量统煤系; 3 一燕山期花岗岩; 4 -印支斯花岗岩; 5 - 向科轴 (2) 大田复 向斜; (4)龙岩复向科); 6 - 背科轴 (3)太华 - 长塔背斜);7 一 断层 (5)政和-大埔断裂, (3)晋江断裂);

1993-04-20 收稿, 199402-07 收修改稿.

*国家自然科学基金资助项目. 
育组成平放或斜放的 $\mathrm{W}$ 型叠褶褶䏢. 规模相当巨大, 在露头上可见到的幅度有几十至百余 米,而剖面上可达几百米. 在垂直 $x$ 轴的 $y z$ 剖面上呈椭圆形、扁平形、扁圆形、铁饼形等 (图 2)等,而且其中心部分可以近圆形或桃形等 (图 3). 剑鞘褶皱的轴面都与应变椭球体的 $x y$ 面平行. 在剑鞘近核部的砂岩层面发育近于沿 $x$ 轴延伸的擦沟、擦痕等冷线理. 另外微观分 析石英颗粒长轴由于压溶造成的优选方位也与剑鞘褶皱的长轴方向一致. 这些都说明剑鞘的 长轴是沿着强烈剪切拉伸的 $x$ 轴发育的, 它确实是一种典型的 $\mathrm{a}$ 型褶皱.

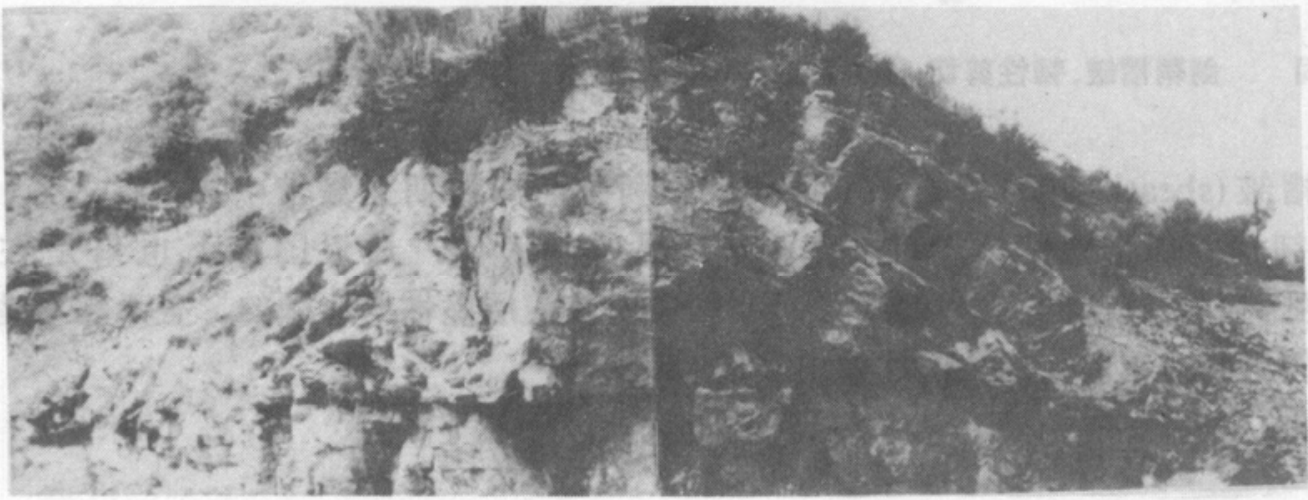

图 2 福建大田县上京矿区由下二叠统童子岩组砂岩构成的铁饼状剑鞘 褶皱横断面图(右方为 $145^{\circ}$ )

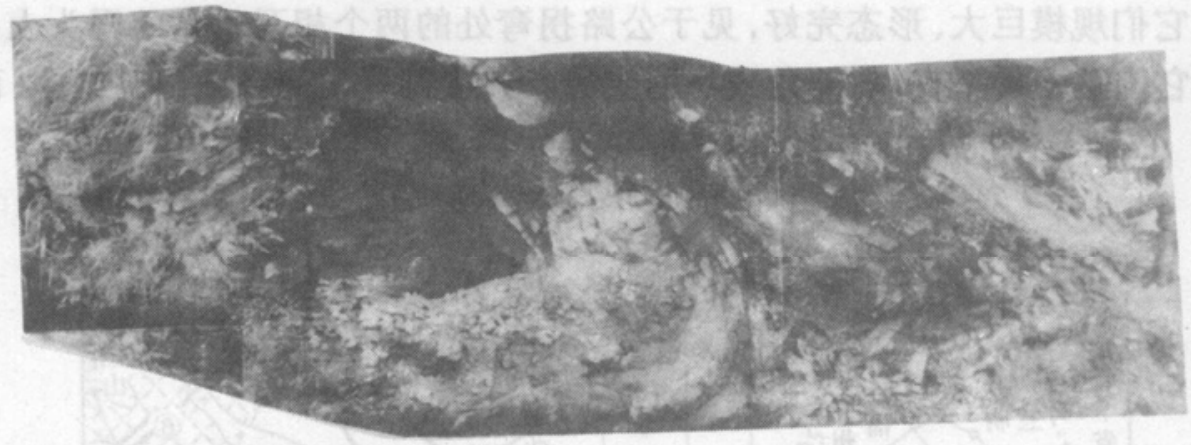

图 3 福建龙岩市翠屏山区由童子岩组薄层砂岩构成的剑鞘褶皱 扁圆状, 中心近桃形,右方为东

\section{2 应变 环 境}

在翠屏山和上京矿区见到的剑鞘褶皱决不是深层次高温高压环境中的产物. 这里二叠系 细砂岩、粉砂岩等是未经变质的标准沉积岩; 就在剑鞘褶皱右上翼的层面上还见有二叠系的 猫眼鳞木化石. 它们当中的剪切、滑移、变形被侏罗到白严系地层所覆盖, 根据覆盖前岩层厚 度推算, 变形时埋藏深度最多只有 $3.5 \mathrm{~km}$, 即使把后期的上覆地层都加上也远远不到 $10 \mathrm{~km}$. 根据微观构造提供的资料: 显微镜下观察主要是脆韧性的形变特征,很少见到动态重结晶, 更不 见糜棱岩; 透射电子显微镜下仅见到一些长条状或束状的变形双晶. 所以它们的应变环境处 于冷加工状态. 而且剑鞘褶皱及其他强烈流变的煤岩层, 仅在翠屏山、上京等很有限的范围 内出现, 无论是横向或纵向它们都可突然地被剪切滑移的脆性滑片所替代. 如翠屏山矿北界 
的谢家邦区、东界的黄坑区都是简单 的滑片, 完全不见任何褶皱变形 (图 4(b) ). 其下伏的栖霞灰岩也是构造 极为简单的单斜岩层. 这种浅层次、冷 加工、分布局限、界限分明的强烈韧性 变形必定是地表浅层, 低温, 低压, 而 且是局部动力环境中产生的.

\section{3 形 成 机 制}

地表常温环境下, 只有重力能为 局部地段提供这样强烈流变槢皱的动 力条件. 龙岩翠屏山和大田上京的剪 切流变和剑鞘褶皱正是在华南区域性 伸展滑脱的基础上, 再经重力长期缓

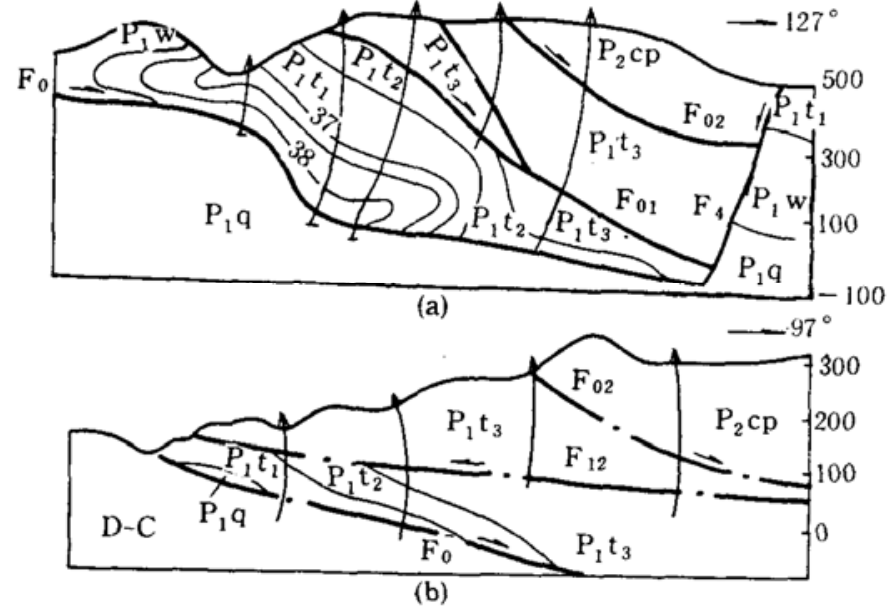

图 4 福建省翠屏山 (a) 与黄坑 (b) 构造剖面对比图 (据勘探资料编绘)

慢作用的特定环境中产生的 ${ }^{[7,8]}$. 在福建省二叠纪煤系中广泛分布的 $F_{01}, F_{02}$ 等伸展型的滑脱 断层是早、中三叠世华南地区强烈的裂陷伸展时, 沿着煤系中的几个巨厚软弱层逐层剪切滑 移作用的结果. 这些断层都沿地层柱中的软弱带分布, 它们既不改变地层的上下层序, 又 都造成一定的层位缺失. 在图 4 的大比例原始图上可推算出它们缺失的层厚. 其中尤以文笔 山页岩与童子岩组煤系之间, 以文笔山页岩为润滑层的 $\mathrm{F}_{0}$ 号 断层最为重要, 它缺失的地层厚 度可在 150- $300 \mathrm{~m}$. 其下伏系统为简单的灰岩单斜岩层; 断层上盘或是滑片 (图 4(b)), 或是 滑褶 (图 4(a)) . 这些滑片、滑褶都是由北西向南东, 逆着区域挤压动力的方向由上而下 滑动的. 特别是在那些赖以滑动的基底斜坡由陡变缓处, 运动速率由于变缓受阻而极为缓 慢, 所以一般都形成了以平卧褶铍为主的固流褶皱。翠屏山和上京矿区在这些韧性剪切最强烈 地段出现了剑鞘褶皱. 用离心计做模拟实验时设计了一个明显的坡度变化以加大滑动前端的 阻力. 实验结果不仅在由陡变缓处出现了平卧褶皱; 而且其表层前端也出现了向滑动方向凸 出伸突的鞘状褶皱,但其前后很快变为单斜岩层. 这个实验结果完善解释了翠屏山和上京等 地分布局限、界限截然的流变褶铍以及其前锋出现的剑鞘褶皱.

\section{4 结 语 与 讨 论}

华南二叠系煤系中出现的剑鞘褶皱不仅在福建存在, 作者在江西也曾见到, 它们确实是重 力滑动长期蠕变的结果. 它们的发育条件除了要求滑体本身是界面发育, 并夹有粘土岩的薄层 岩层和底界有巨厚的润滑层外; 还要有先期的顺层滑面以降低滑带附近的摩擦阻力; 当然在 特定条件下, 重力的低应力和低应变速率的长期缓慢蠕变作用是决不少的动力条件. 它们滑 移的距离并不很远, 翠屏山区通过平衡地质剖面恢复工作计算其缩短量只有 $-38.61 \%$, 而上 京地区所谓 “红绸舞式” 的褶彼也只有 $-42.65 \%$. 值得指出的是这种剑鞘褶皱只在软硬相 间、成层很好的煤系地层中出现; 而且其规模一般较大, 同时岩石内部的粒内滑移变形相当轻 微. 这些也是与深层次韧性剪切带不同的地方. 因为重力滑动构造逐层剪切滑移的应变主要 通过层间界面及其软弱夹层的变形来完成, 这种低应力不可能造成岩石内部颗粒的强烈变 
形. 作者通过大量微观及超微观观测证实岩石中的石英颗粒虽然出现了压溶定向和微弱的 塑性变形, 但总体还属脆韧性变形特征. 这种较轻微内部变形不可能造就尺度很小的剑 鞘褶皱。

温度的增高和应变速率的减缓起等效作用; 高温环境可使岩石发生流变,低应变速率也同 样可使坚硬的岩石产生强烈的屈服变形. 造成剑鞘褶皱的强烈韧性剪切, 并非只限于地壳深 层次的高温、高压形变环境; 地表浅层重力作用也可形成剑鞘褶皱,这个事实打破了国际上把剑 鞘褶皱只能作为深层次韧性剪切带鉴别标志的认识, 也扩展了近年来发现的这种特殊构造形 成的构造层次和环境条件.

\section{参 考 文 献}

[1] Carreras, J., Julivert, M., Santanach, P., J. Struct. Geol., 1980, 12(1/2):5-9.

[2] Borradaile, G., Sarvas, P., Dutka, R. et al., Canadian J. Earth Sciences, 1988, 25(7): 1069-1077.

[ 3] 郑亚东、常志忠,岩石有限应变测量及韧性尊切带, 地质出版社, 北京, 1985, 121- 127.

[4] Synek, J., Vestnik Ustredniho Ustavu Geologickeno., 1991, 66(2): 75-84.

[ 5] Goscombe, B., J. Struct. Geol., 1991, 13(3):299-318.

[6] Mies, J. W., J. Struct. Geol., 1993, 15(8): $983-993$.

[7]王桂梁、马文堘, 地质构造图册, 煤炭出版社, 北京, 1992 10: 80-82.

[8] 王桂梁、王 信、王文杰, 滑脱构造研究, 科学出版社, 北京, 1992, 98- 103. 